\title{
COMPARISON BETWEEN MESH FIXATION USING TACKS AND NON-MESH FIXATION DURING TOTAL EXTRA PERITONEAL (TEP) LAPAROSCOPIC INGUINAL HERNIA REPAIR
}

\author{
By \\ Mohamed Abd El-Halim, Selim El-Nemr, Mohammed Hedaya*, and \\ Ayman Helmy Ibrahim \\ Departments of General Surgery, Faculty of Medicine - Al-Azhar University, and Theodor \\ Bilharz Research Institute (TBRI)* \\ E-mail: m.elhalim1987@gmail.com
}

\begin{abstract}
Background: Inguinal hernia repair is the most common procedure in general and visceral surgery worldwide. Over the past two decades, laparoscopic inguinal hernia repair has become more and more popular.
\end{abstract}

Objective: To enhance outcome of TEP, test feasibility, and count the cost of mesh fixation using staples and non-mesh fixation.

Patients and methods: This study was conducted in Theodor Bilharz Research institute [TBRI] and AlAzhar University Hospitals during the period from December 2017 to April 2019.This study included 40 patients with inguinal hernia underwent TEP repair. Patients were divided in to two equal groups: Group A include patients underwent TEP repair with no mesh fixation, and Group B underwent TEP repair using tack fixation of mesh.

Results: Regarding operative time, it was slightly longer in mesh fixation group. No intraoperative complications have been encountered in groups including bleeding, peritoneal tear or visceral injuries. Regarding postoperative period, there was no difference in the postoperative parameters between both groups including pain, hospital stay and recurrence.

Conclusion: Totally extra-peritoneal approach (TEP) was an acceptable procedure for inguinal hernia repair with less visceral and vascular injuries. No difference in outcome between mesh fixation and non-mesh fixation in TEP repair of inguinal hernia.

Keywords: Mesh fixation, Non-mesh fixation, TEP, Laparoscopic Inguinal Hernia Repair.

\section{INTRODUCTION}

With the development of laparoscopic techniques, laparoscopic hernia repair is increasingly being used to treat inguinal hernias. Among these techniques, transabdominal preperitoneal (TAPP) repair and totally extraperitoneal (TEP) procedures are the most frequently used laparoscopic hernia repairs. TAPP and
TEP repairs have been reported to reduce the occurrence of postoperative pain, shorten the length of the hospital stay, and accelerate the recovery of patients ( Lyu et al., 2020).

During the past few years, the Royal College of Surgeons of England investigated the current evidence and recently recommends a laparoscopic 
approach for the following: bilateral hernias, recurrent hernias (if the primary repair was open), any groin hernia in a woman, and hernias in men who are young and active or who have pain as a main symptom of hernia (Royal College of Surgeons of England, 2013). Applying tacks or staples to keep the mesh sound or repair the peritoneal window during a TAPP repair may contribute to the development of postoperative pain in about $10 \%$ of cases. Also, TAPP carries higher visceral injury than TEP (Sajid et al., 2012).

Several studies have shown that nonfixation is a viable option without an increased risk for recurrence, and that it also has the advantages of shorter operative time, less chronic groin pain, no injury to the vas deference, gonadal vessels, inferior epigastric vessels, and an overall improved quality of life when compared with tucker fixation (Teng et al., 2011).

Individual surgeon preference plays a major role in the decision regarding the type of fixation device used (Kaul et al., 2012). Many surgeons perform nonfixation of the mesh to avoid fixation device-associated chronic pain (Lo et al., 2019). However, where fixation is preferred, the use of 'tacks' was initially employed in both TEP and TAPP techniques. Stark et al. highlighted the need to reduce the number of tacks in laparoscopic inguinal hernia surgery to reduce the risk of nerve irritation and the consequent impact on post-operative pain (Shah et al., 2014).
The aim of this work was to enhance outcome of TEP, test feasibility, and count the cost of mesh fixation using staples, non-mesh fixation.

\section{PATIENTS AND METHODS}

This study was conducted on 40 patients with inguinal hernia presented to Theodor Bilharz Research Institute (TBRI) and Al-Azhar University Hospitals during the period from December, 2017 to April, 2019. Patients were divided into two equal groups (Group A and Group B). Group A represented patients who underwent TEP repair of inguinal hernia without mesh fixation, and Group B represented patients who underwent TEP repair of inguinal hernia with mesh fixation. All patients were evaluated before the operation by full history taking, clinical examination, and full investigations included:

A. Laboratory: Full blood count, liver function tests [LFTs], kidney function tests [KFTs] and bleeding profile.

B. Radiological: Pelvi- abdominal ultrasound.

All patients consented to undergo conversion to TAPP technique or open technique if necessary. Foley's indwelling catheter placed prior to surgery, removed when the patient can move after surgery. In both groups, we used $12 \times 15 \mathrm{~cm}$. polyprolene mesh, with insertion of two small liver clips at its edge[ for radiological follow up after the operation] (Fig.1) (Fig.2). 


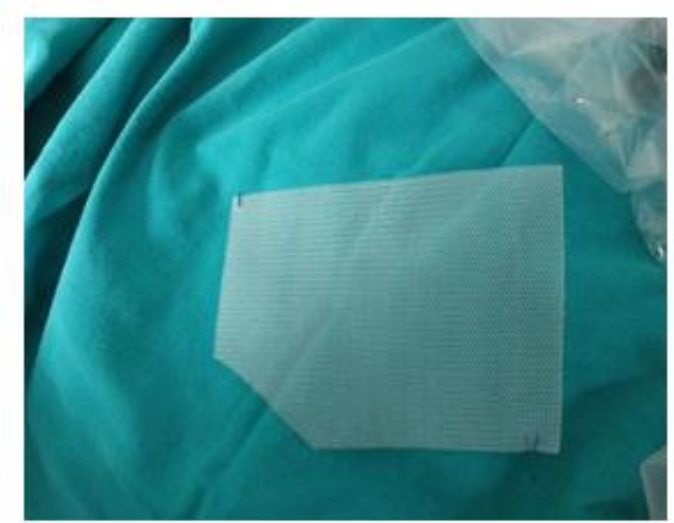

Fig.(1):preparation of mesh with marking of its edges with two clips

During postoperative hospital stay, pain assessment was done using visual analogue scale, and analgesia if needed. The patients were discharged to home after $24 \mathrm{hrs}$ after the operation with oral antibiotics, oral anti edematous and analgesic on need. Patients were asked to return for follow up in outpatient clinic about one week after surgery. Follow up at 1 month, 3 months and 6 months.

\section{Statistical analysis:}

The data were statistically described in terms of mean standard deviation (SD),

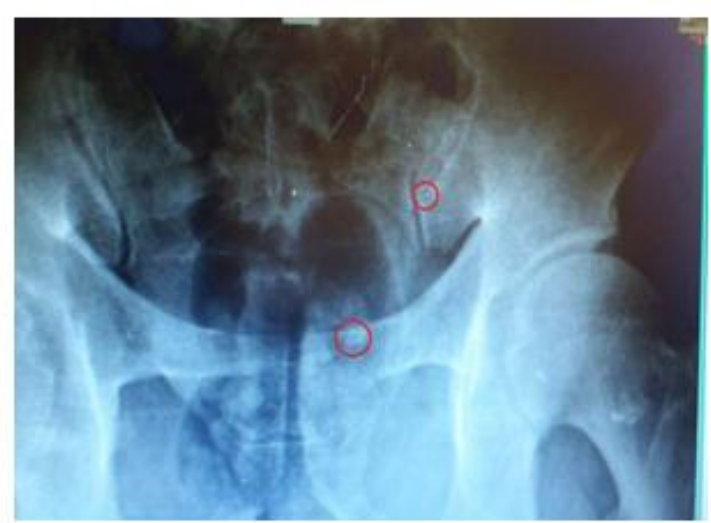

Fig.(2):Two liver clips marking mesh margins in postoperative $x$-ray follow up

median and range, or frequencies (number of cases) and percentages when appropriate. For comparing categorical data, the "Chi square test" was performed. "P values" less than " 0.05 " was considered statistically significant. All statistical calculations were done using the program "IBM SPSS Statistics" (Statistical Package for the Social Science; IBM Corp., USA) and the Graph Pad Prism.

\section{RESULTS}

The age of the patients ranged between 22-56 years old with mean \pm SD $38.85 \pm$

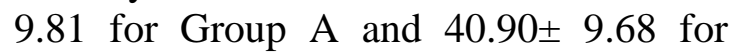
Group B (Table 1). All patients of both groups were males (100\%).

Group A included 9 funicular type and 11 bubonocele. Group B 11 funicular type and 9 bubonocele. Regarding operative time, in group $\mathrm{A}$, operative time ranged between 40-62 minutes with mean 50.95 while in group $\mathrm{B}$, operative time ranged between 51-73 with mean 64.20 (Table 1). The operative time was calculated from inflation of the pre-peritoneal space till the end of the procedure. No cases of conversion to TAPP or open approach in both groups. 
Table (1): Age, Operation time in minutes, and Degree of hernia distribution of the patients

\begin{tabular}{|c|c|c|c|c|c|c|}
\hline \multirow{2}{*}{\multicolumn{2}{|c|}{$\begin{array}{ll}\text { Variables } & \text { Groups } \\
\end{array}$}} & \multirow{2}{*}{\multicolumn{2}{|c|}{$\begin{array}{c}\text { Group A } \\
\mathbf{N}=\mathbf{2 0}\end{array}$}} & \multicolumn{2}{|c|}{ Group B } & \multirow{2}{*}{ P-value } \\
\hline & & & & & & \\
\hline \multicolumn{2}{|c|}{ Age } & \multicolumn{2}{|c|}{$\begin{array}{c}\text { Range }(22-56) \\
\text { Mean } \pm \text { SD }(38.85 \pm 9.81)\end{array}$} & \multicolumn{2}{|c|}{$\begin{array}{c}\text { Range }(23-54) \\
\text { Mean } \pm \text { SD }(40.90 \pm 9.68)\end{array}$} & 0.510 \\
\hline \multicolumn{2}{|c|}{$\begin{array}{c}\text { Operation time in } \\
\text { minutes }\end{array}$} & \multicolumn{2}{|c|}{$\begin{array}{c}\text { Range (40-62) } \\
\text { Mean } \pm \text { SD }(50.95 \pm 6.786)\end{array}$} & \multicolumn{2}{|c|}{$\begin{array}{c}\text { Range (51-73) } \\
\text { Mean } \pm \text { SD }(64.20 \pm 6.445)\end{array}$} & $<0.000$ \\
\hline \multirow{2}{*}{$\begin{array}{c}\text { Degree of } \\
\text { hernia }\end{array}$} & Funicular & 9 & $45 \%$ & 11 & $55 \%$ & \multirow{2}{*}{0.527} \\
\hline & bubonocele & 11 & $55 \%$ & 9 & $45 \%$ & \\
\hline
\end{tabular}

Regarding postoperative complications, there were 2 cases in each group of scrotal edema which resolved spontaneously within one month. There was one case of recurrence in group A after 2 months of operation, which has been repaired by laparoscopic assisted approach. There were no cases of recurrence in group B. There was one patient suffered from urine retention in group A. In group B, there were 2 cases with postoperative urine retention. Two cases managed conservatively with suprapubic hot fomentation, one case need insertion of urinary catheter.
For monitoring and comparing the postoperative pain intensity between two groups, a visual analogue scale (VAS) with a $10 \mathrm{~cm}$ score ranging from 'no pain' (score 0) to 'worst possible pain'(score 10).After the patients has been adequately instructed about the range for measuring pain, they selected a value on the scale (between 0 and 10).Pain score analysis showed no statistically significant difference postoperatively regarding early postoperative pain in both groups. No cases of chronic groin pain in both groups during the study period. All patients have been discharged from the hospital within 24-48hrs after surgery (Table 2).

Table (2): post-operative complications and hospital stay:

\begin{tabular}{|c|c|c|c|c|c|}
\hline \multirow{3}{*}{$\begin{array}{l}\text { Variables } \\
\text { Scrotal edema }\end{array}$} & \multirow{2}{*}{\multicolumn{2}{|c|}{\begin{tabular}{|l} 
Group A \\
$\mathbf{N}=\mathbf{2 0}$ \\
\end{tabular}}} & \multirow{2}{*}{\multicolumn{2}{|c|}{\begin{tabular}{|l} 
Group B \\
$\mathbf{N}=20$ \\
\end{tabular}}} & \multirow{3}{*}{$\begin{array}{c}\text { P-value } \\
1.000 \\
\end{array}$} \\
\hline & & & & & \\
\hline & 2 & $10 \%$ & 2 & $10 \%$ & \\
\hline $\begin{array}{c}\text { Incidence of } \\
\text { recurrence }\end{array}$ & 1 & $5 \%$ & 0 & $0 \%$ & 1.000 \\
\hline Urine retention & 1 & $5 \%$ & 2 & $10 \%$ & 0.548 \\
\hline $\begin{array}{c}\text { Post-operative pain } \\
\text { day } 1\end{array}$ & Mean & $\begin{array}{l}5-9) \\
5 \pm 1.146)\end{array}$ & Mean & $\begin{array}{l}-9) \\
0 \pm 1.152)\end{array}$ & 0.342 \\
\hline $\begin{array}{c}\text { Post-operative } \\
\text { hospital stay }\end{array}$ & $\begin{array}{l}1 \\
\text { Mean }\end{array}$ & $\begin{array}{l}-2) \\
05 \pm .224)\end{array}$ & $\begin{array}{r}\text { I } \\
\text { Mean }\end{array}$ & $\begin{array}{l}-1) \\
00 \pm .000)\end{array}$ & 0.323 \\
\hline
\end{tabular}

\section{DISCUSSION}

The concepts in inguinal hernia repair have seen a progressive shift toward the increased dependence upon mesh during the last four decades. The milestones were tension-free hernioplasty by Lichtenstein et al. (Garg et al., 2011). When the mesh was placed in the pre-peritoneal space it was perceived that there was a risk that it would move or get folded, which could increase the risk of hernia recurrence. Thus, the need to fix the mesh was a logical step. However, Stoppa et al. 1996 
demonstrated that non-fixation of mesh during open pre-peritoneal repair was safe.

Subsequently, in 1999, the safety of non-fixation of mesh during laparoscopic surgery was demonstrated in total extraperitoneal (TEP) repair by Ferzli et al. (Bittner et al., 2015). The TAPP procedure has the advantage of ease of learning, because there are no space constraints. However, the major disadvantage is entry into the peritoneum. The anatomy and placement of mesh are similar to TEP repair but without any space limitations (Bansal et al., 2013). Since then several studies have shown the reliability of non-fixation of mesh in both TEP and TAPP (Garg et al., 2011). In spite of few randomized control trials (RCTs) and retrospective studies with a large number of patients demonstrating the safety of non-fixation of mesh in TEP, mesh non-fixation has yet to be recommended in TEP inguinal hernia repair. So, in this study we have tried to determine if there is a difference between mesh fixation and non-mesh fixation during TEP repair of inguinal hernia.

Regarding postoperative acute pain, there was no significant difference in postoperative pain in both groups in the current study. Teng et al. (2011) and Sajid et al. (2012) found that there's no significant difference in postoperative pain between mesh-fixation and nonfixation groups. Bansal et al. (2011) and Garg et al. (2011) detected significantly lower rate of postoperative pain in the non- fixation group.

Raghu et al. (2016) found that postoperative pain was significantly less in the non-fixation group compared with the mesh fixation group. Also, there were no encountered cases of chronic groin pain in this study after 6 months follow up postoperatively. This result was consistent with Raghu et al. (2016), and Buyukasik et al. (2017), where all patients irrespective of the groups did not experience any pain through 6 months postoperatively. In a large case study by Tam et al. (2010), it was found that only three patients complained of neuralgia in each group, revealing no significant difference in the incidence of neuralgia between groups. In contrast to our study, different studies showed increased incidence of chronic groin pain in mesh fixation approach like Garg et al. in 2009 (Sajid et al., 2012). Any difference in pain due to mesh fixation would be chronic in nature as it would manifest itself after the early pain subsided. Nerve entrapment by the tacks could be responsible for this.

In 2008, Taylor demonstrated that the incidence of chronic pain increases proportionately with the number of tacks used and this association reached statistical significance when more than six tacks were used. However, their analysis found that in the overwhelming majority of these patients, the pain was mild and caused little or no interference with daily life (Garg et al., 2011). However, Bansal et al. (2013) found that the prevalence of numbness over the upper part of the scrotum and thigh at 1 and 3 months of follow-up was seen in a few patients with repair by non-fixation technique. There was also a testicular pain and discomfort in $2.6 \%$ of the patients.

Hernia recurrence occurred in one patient in mesh non-fixation group in the current study. Ayyaz et al. (2015) found in 
their study that only one recurrence was encountered in 5-year follow up in the group of non-fixation. However, in the study by Sajid et al. (2012), four patients developed recurrent inguinal hernia in 691 patients having mesh fixation, and three patients developed recurrent inguinal hernia in 691 patients having non-mesh fixation. On the contrast, Garg et al. (2011), Raghu et al. (2016) and Buyukasik et al. (2017) found that no increase in recurrence rate when the mesh was not fixed during TEP.

Choy et al. (2004) showed that an unfixed mesh of $15 \mathrm{~cm} \mathrm{x} 15 \mathrm{~cm}$ could not be induced to move by on-table cycles of hip flexion and was confirmed on inspection of the mesh by re laparoscopy of the pre-peritoneal space.

In the current study, there was no encountered peritoneal tear in any case of both groups. Swarker et al. (2017) reported some cases of pnumoperitoneum, relieved with the veress needle. Moreover, in a study by Liew et al. (2017) with tucker mesh fixation technique, pneumoperitoneum was found in $8.8 \%$ of patients.

No cases needed conversion to open hernia repair or TAPP procedure, and there were no bowel and visceral injuries in our study. This was similar to the results of study by Krishna et al. (2012) that was one conversion to TAPP technique in the study of Bansal, where 160 patients underwent laparoscopic TEP inguinal hernia repair without mesh fixation (Bansal et al., 2013).

Regarding other postoperative complications, in this study, we had one case of postoperative groin hematoma in non-fixation group which resolved within one month with no intervention. Two patients in each group (10\% each) had scrotal edema, with no statistically significance. Garg et al. (2011) found in their study that the proportion of patients with seroma formation was also similar in both groups [fixation, (10.4\%) and nonfixation, (15.4\%)] Swarker et al. (2017) had one patient with seroma formation, which healed by itself. They found that $2.6 \%$ of patients who underwent TEP with mesh fixation had scrotal pain and edema. Postoperative surgical emphysema was present in $25 \%$ of patients in each group in this study, with no statistically significant differences, and resolved spontaneously within few hours postoperatively. Mohamed et al. (2019) found that postoperative surgical emphysema was present in $10 \%$ patients in each group. All these cases were treated conservatively and resolved within 2-3 days postoperatively.

The mesh fixation group had a slightly longer time than mesh non-fixation group with insignificant difference. Also, Buyukasik et al. (2017) found in their study that the mean operative time is statistically insignificant. On the contrast, Garg et al. (2011) reported that the operating time was significantly longer for the fixation group more than non-fixation. Moreover, Tam et al. (2010) stated that there was a significantly longer operative time for mesh fixation operations.

There were no statistically significant differences in the mean hospital stay in our study. This was agreed also by the studies by Garg et al. (2011) and Buyukasik et al. (2017). Meyer et al. (2013) did TEP repair without mesh fixation in 157 patients, and the mean 
hospital stay was less than $12 \mathrm{~h}$ in $95 \%$ of the patients.

\section{CONCLUSION}

Totally extra-peritoneal approach (TEP) is an acceptable procedure for inguinal hernia repair with less visceral and vascular injuries. No difference in outcome between mesh fixation and nonmesh fixation in TEP repair of inguinal hernia.

Conflicts of interest: No conflicts of interest were encountered.

\section{REFERENCES}

1. Ayyaz, M., Farooka, M. W., Malik, A. A., Khan, A., Mansoor, R., Toor, A. A. and Khokhar, H. A. (2015): Mesh fixation vs. non-fixation in total extra peritoneal mesh hernioplasty. J Pak Med Assoc., 65(3): 270-272.

2. Bansal, V. K., Misra, M. C., Babu, D., Victor, J., Kumar, S., Sagar, R., and Rewari, V. (2013): A prospective, randomized comparison of long-term outcomes: chronic groin pain and quality of life following totally extra peritoneal (TEP) and trans abdominal preperitoneal (TAPP) laparoscopic inguinal hernia repair. Surgical endoscopy, 27(7): 23732382.

3. Bansal, V. K., Misra, M. C., Kumar, S., Rao, Y. K., Singhal, P., Goswami, A. and Chabra, A. (2011): A prospective randomized study comparing suture mesh fixation versus tacker mesh fixation for laparoscopic repair of incisional and ventral hernias. Surgical Endoscopy, 25(5): 1431-1438.

4. Bittner, R., Montgomery, M.A. and Arregui, E. (2015): Update of guidelines on laparoscopic (TAPP) and endoscopic (TEP) treatment of inguinal hernia
(International Endohernia Society). Surg Endosc 29:289-321.

5. Buyukasik, K., Ari, A., Akce, B., Tatar, C., Segmen, O. and Bektas, H. (2017): Comparison of mesh fixation and non-fixation in laparoscopic totally extra peritoneal inguinal hernia repair. Hernia, 21(4): 543-548.

6. Choy, C., Shapiro, K., Patel, S., Graham, A. and Ferzli, G. (2004): Investigating a possible cause of mesh migration during totally extra peritoneal (TEP) repair. Surgical Endoscopy and Other Interventional Techniques, 18(3): 523-525.

7. Garg, P., Nair, S., Shereef, M., Thakur, J. D., Nain, N., Menon, G. R. and Ismail, M. (2011): Mesh fixation compared to no fixation in total extra peritoneal inguinal hernia repair: a randomized controlled trial in a rural center in India. Surgical endoscopy, 25(10): 3300-3306.

8. Girish, T. U. and BJ, S. C. (2016): A prospective comparative study of total extra peritoneal inguinal hernia repair: fixation versus without fixation of the mesh. International Surgery Journal, 4(1): 166-169.

9. Kaul, A., Hutfless, S., Le, H., Hamed, S. A., Tymitz, K., Nguyen, H. and Marohn, M. R. (2012): Staple versus fibrin glue fixation in laparoscopic total extra peritoneal repair of inguinal hernia: a systematic review and meta-analysis. Surgical Endoscopy, 26(5): 1269-1278.

10. Krishna, A., Misra, M. C., Bansal, V. K., Kumar, S., Rajeshwari, S. and Chabra, A. (2012): Laparoscopic inguinal hernia repair: trans abdominal preperitoneal (TAPP) versus totally extra peritoneal (TEP) approach: a prospective randomized controlled trial. Surgical Endoscopy, 26(3): 639-649. 
11. Liew, W., Wai, Y. Y., Kosai, N. R. and Gendeh, H. S. (2017): Tackers versus glue mesh fixation: an objective assessment of postoperative acute and chronic pain using inflammatory markers. Hernia, 21(4): 549-554.

12. Lo CW, Tsai YC, Yang SS, Hsieh CH and Chang SJ. (2019): Comparison of short- to mid-term efficacy of no fixation and permanent tack fixation in laparoscopic total extra peritoneal hernia repair: A systematic review and metaanalysis. Ci ji yi xue za zhi $=$ Tzu-chi Medical Journal, 31(4): 244-253.

13. Lyu Y, Cheng Y, Wang B, Du W and Xu Y. (2020): Comparison of endoscopic surgery and Lichtenstein repair for treatment of inguinal hernias: A network meta-analysis. Medicine, 99(6): e19134.

14. Meyer, A., Dulucq, J. L. and Mahajna, A. (2013): Laparoscopic hernia repair: no fixation mesh is feasibly?. Arquivos brasileiros de cirurgia digestiva: $\mathrm{ABCD}=$ Brazilian archives of digestive surgery, 26(1): 27.

15. Mohamed, H. E. D., ElSheikh, M., Barakat, H. and Abdelhamid, A. F. (2019): A comparative study of mesh fixation versus no fixation in laparoscopic totally extra peritoneal inguinal hernia repair. The Egyptian Journal of Surgery, 38(2): 348-357

16. Raghu RS, Girish TU and Chandra BJ. (2016): A prospective comparative study of total extra-peritoneal inguinal hernia repair: fixation versus without fixation of the mesh. Int Surg J., 4:166169.

17. Royal College of Surgeons of Enland (2013): Groin hernia guidelines.
18. Sajid, M. S., Ladwa, N., Kalra, L., Hutson, K., Sains, P. and Baig, M. K. (2012): A meta-analysis examining the use of tacker fixation versus no-fixation of mesh in laparoscopic inguinal hernia repair. International Journal of Surgery, 10(5): 224-231.

19. Sawarkar, P., Zade, R., Dhamanaskar, S., Gathe, B., Sawardekar, P. and Khade, A. (2017): Feasibility of laparoscopic inguinal hernia repair (TEP) in rural centre in India. International Surgery Journal, 4(7): 2336-2341.

20. Shah, N. S., Fullwood, C., Siriwardena, A. K. and Sheen, A. J. (2014): Mesh fixation at laparoscopic inguinal hernia repair: a meta-analysis comparing tissue glue and tack fixation. World Journal of Surgery, 38(10): 2558-2570.

21. Tam, K. W., Liang, H. H., and Chai, C. Y. (2010): Outcomes of staple fixation of mesh versus nonfixation in laparoscopic total extraperitoneal inguinal repair: a meta-analysis of randomized controlled trials. World Journal of Surgery, 34(12): 3065-3074.

22. Teng, Y. J., Pan, S. M., Liu, Y. L., Yang, K. H., Zhang, Y. C., Tian, J. H. and Han, J. X. (2011): A meta-analysis of randomized controlled trials of fixation versus no fixation of mesh in laparoscopic total extra peritoneal inguinal hernia repair. Surgical Endoscopy, 25(9): 2849-2858. 


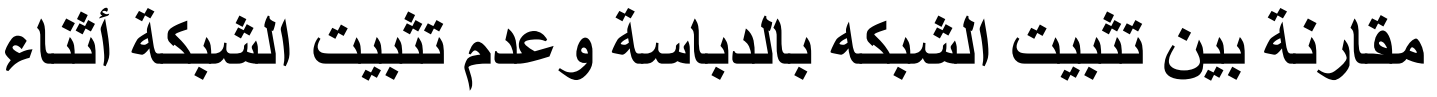

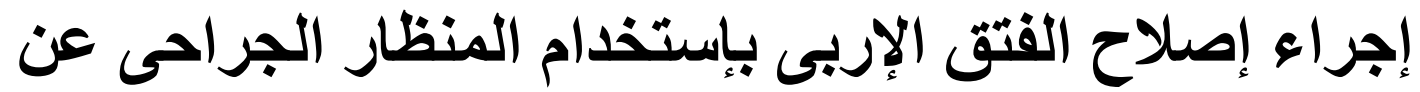

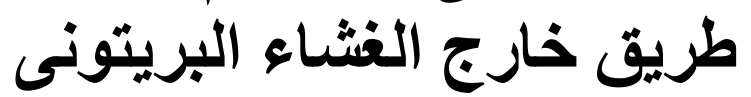

محمد احمد عبد الحليم احمد، سليم سعيد عبد الرحمن النمر، محمد سعيد محمد حداية*ث،

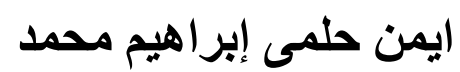

قسمى الجراحة العامة بكلية الطب، جامعة الأزهر ومعهد ثيودور بلهارس للأبحاث*

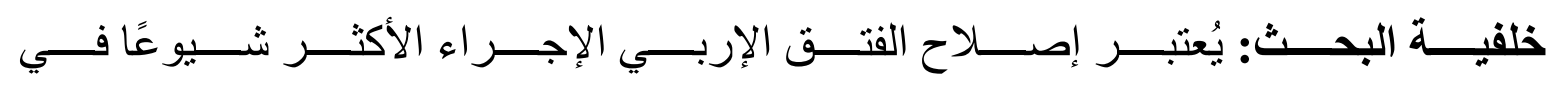

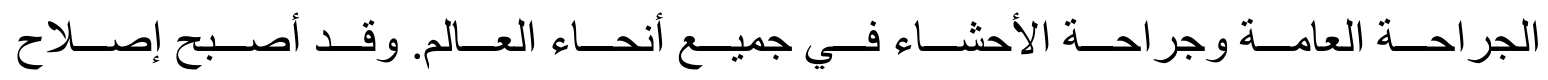
الفتق الأربي بالمنظار أكثر شيو عًا على مدى العقدين الماضيين.

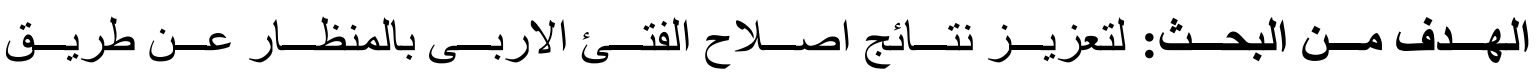

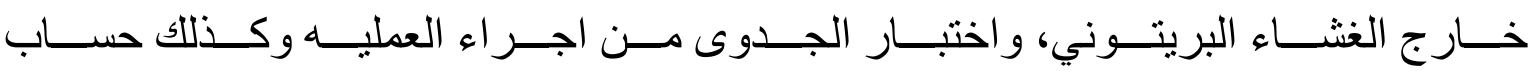
تكلفة تثييت الثبكة باستخدام الدبابيس و التنبيت غير الثبكي.

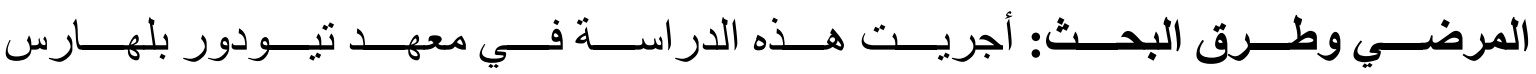

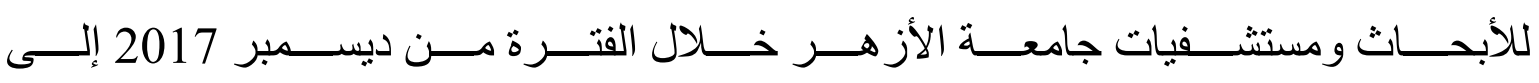

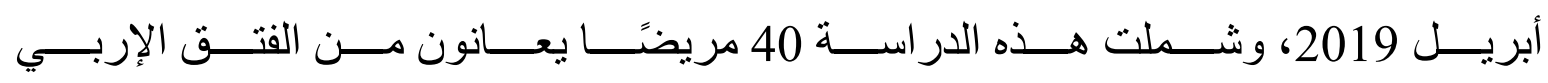

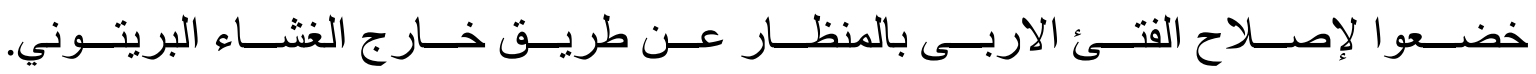

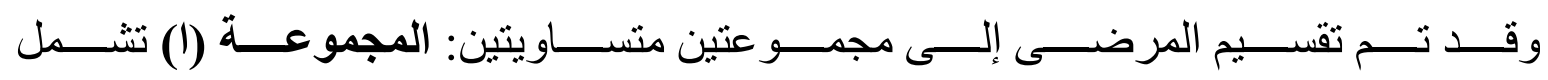

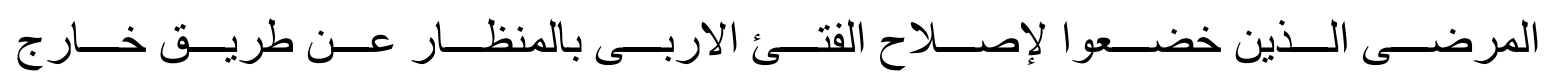

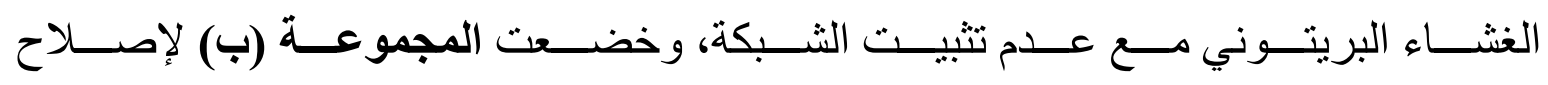

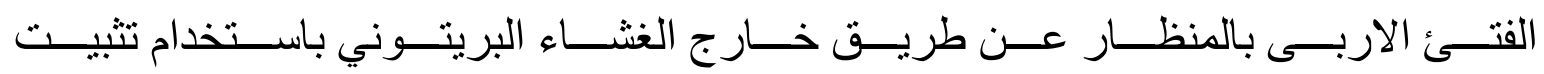

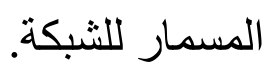

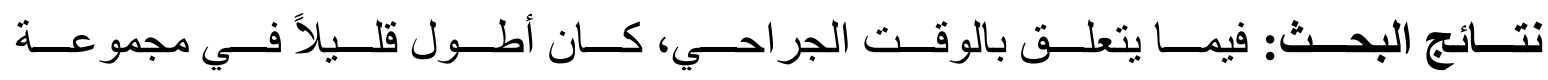

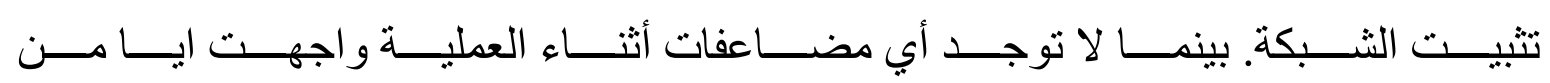

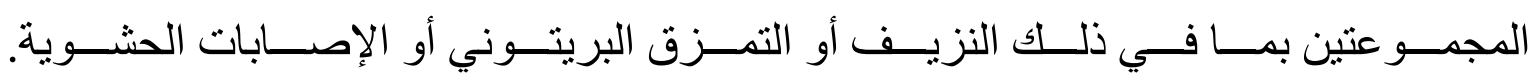




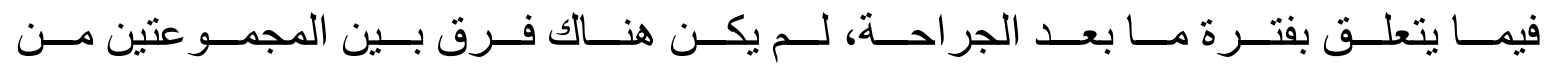

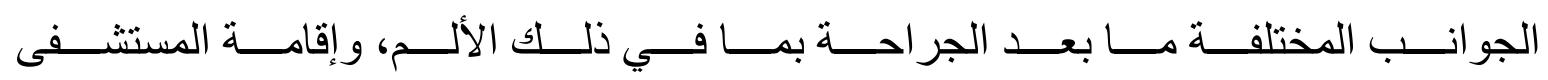
وتكر ارها.

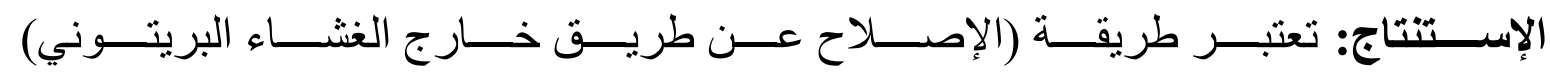

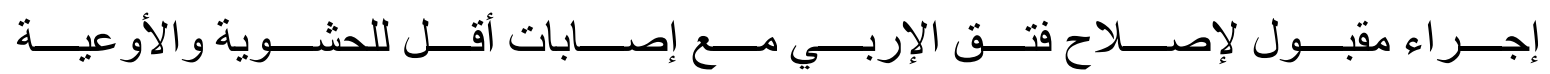

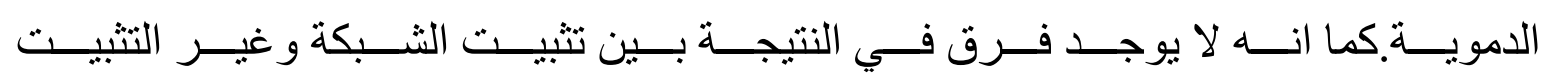

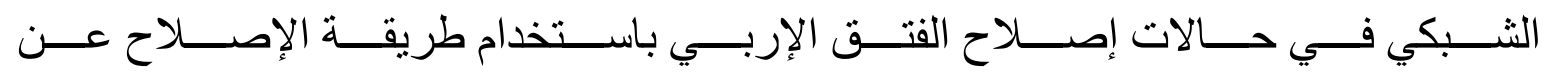
طريق خارج الغشاء البريتوني. 